\title{
Description of new species of leaf miners (Diptera Agromyzidae) associated with leguminous host described from northern India
}

\author{
Ram Bahadur Thapa \\ Department of Zoology, Post Graduate Campus, T.U., Biratnagar, Nepal \\ E-mail:niwaj@yahoo.com
}

\begin{abstract}
A total of 28 species of agromyzid flies belonging to 7 genera have been reared and described on 34 different leguminous host -plants from Pantnagar, Nainital, Northern India. 13 agromyzid flies have been described as new species viz., Japanagromyza species nova (sp.n.) ex leaves of Pueraria phaseoloides (Roxb.) Benth; Liriomyza sp.n. ex leaves of Vicia sativa Linn.; Liriomyza sp.n. ex leaves of Vicia faba Linn.; Malanagromyza sp.n. ex stems of Cassia sp.; Melanagromyza sp.n. ex stems of Pisum sativum Linn. Melanagromyza sp.n. ex stems of Trifolium pratense Linn.; Melanagromyza sp.n. ex stems of Vicia faba Linn.; Ophiomyia sp.n. ex stems of Pueraria Phaseoloides (Roxb.) Benth; Ophiomyia sp.n. ex stems of Sesbania aculeata Pers.; Ophiomyiz sp.n. ex stem of Vigna mungo (Linn.) Heeper and Ophiomyia sp.n. ex stems of Vigna mungo (Linn.) Heeper.

Large numbers of host plants have been recorded as new host for various agromyzid species. More than one thousand male genitalia slides have been prepared for this study. Variations in morphology and genitalia characters have also been illustrated within the species.
\end{abstract}

Key words: Leaf miners, Diptera, Agromyzidae, new species, leguminous host, India.

\section{Introduction}

The members of the family Agromyzidae (Cyclorraphous Diptera) are properly known as leaf miners. Their larvae are exclusively internal plant feeders. Extensive damage is done to several cultivated leguminous crops and weeds. There are 2000 species of agromyzid flies known in the world. This present investigation has added 13 more new species of leaf miners in the world record.

Sehgal et al. (1977-80) has reported 25 different species of leguminous host plants in Northern India, to which agromyzid flies of 8 genera and eleven species are associated. Singh and Ipe (1973) have reported 10 species of agromyzid flies associated with 17 species of leguminous crops. Spencer (1973) has recorded 45 legume hosts infested by 41 species of agromyzid flies throughout the world.

\section{Materials and Methods}

The research was carried out at Govind Ballabh Pant University of Agriculture and Technology, Pantnagar (Nainital) which is situated at $29^{\circ} \mathrm{N}$ latitude, $79.3^{\circ} \mathrm{E}$ longitude 
and at an altitude of $243.84 \mathrm{~m} \mathrm{msl}$ in terai region of the foot hills of Shiwalik ranges of the Himalayan region having humid subtropical climate.

Approximately 1000 male flies were reared and dissected during investigation and equal numbers of male genitalia slides were prepared. Morphological detail of adult flies and genitalia were studied, characterised and illustrated.

\section{Results and Discussion}

The generic concept used in this study has been adopted from Sasakawa (1960, 1961, 1981, 1982, 1986), Spencer (1963, 1964, 1973, 1977, 1981, 1982, 1985), Singh and Ipe (1973), Sehgal et al. (1980), Sehgal (1987) and Spencer and Stayskal (1986).

An attempt has been made to study all the existing species which could be reared during the survey. Apart from describing a new species, detailed morphological variations and differences in genitalia characters among the members within the species have also been carefully evaluated and illustrated wherever felt necessary. Besides describing morphological and genitalia characters, their biology and host plants were also studied. In addition to re-describing 15 known species, 13 species are described and new names have been proposed to them as per International Rules of Zoological Nomenclatures.

\section{Japanagromyza sp. n. ex Leaves of Pueraria phaseoloides (Roxb.) Benth.}

Proposed name: Japanagromyza puerarivora new species (Plate 1).

Derivation of specific name is after the genus of larval food plant, Pueraria phaseoloides (Roxb.) Benth.

Comparison: The members of this species differ from those of tristella (Thomson), indica Ipe and tephrosiae (de Meijere) in having smaller wing length and distinctive characters of genitalia.

Diagnostic characters: Small sized species, wing length $1.26 \mathrm{~mm}$ in male, gena quite narrower, 1/9.5 vertical height of eye, squammae whitish, margin and fringes black, halters top of knob yellowish rest black.
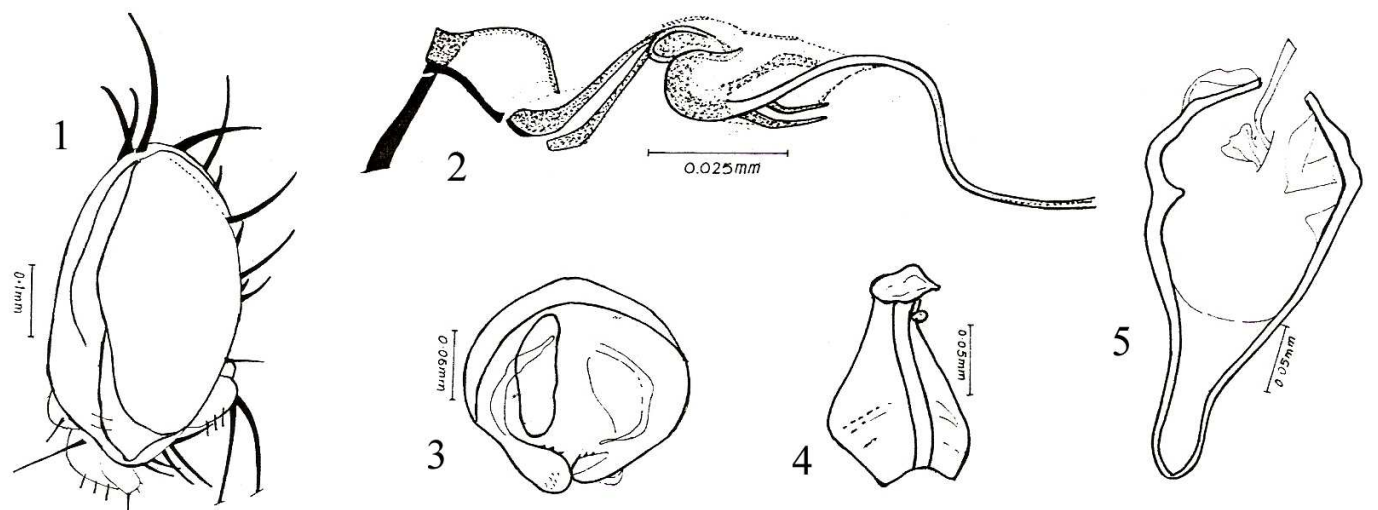

Plate 1. Japanagromyza puerarivora Species nova.

Male genitalia as in figures 2-5, hypandrium (Fig. 5) with narrow side arms, short and broad apodeme; epandrium (Fig. 3) cerci without bristles, surstyli with spines; aedeagus (Fig. 2), basiphallus elongate with two distinct arms, distiphallus elongate with a long 
terminal partially coiled process, ejaculatory apodeme (Fig. 4) broad, blades well extended, bulb large.

Biology: Larvae make blotch mines on the leaves of Pueraria phaseoloides (Roxb.) Benth. during the month of August. Puparia could not be detected.

Geographical distribution: Examined two specimens from India. Uttar Pradesh: Holotype: $\mho^{\top}$ Pantnagar, Nainital, from leaf mines on Pueraria phaseoloides (Roxb.) Benth., coll. 26. viii 87, emerged 29. viii 87; para types: 10 same data.

\section{Melanagromyza sp.n. ex stems of Cassia sp.}

Proposed name: Melanagromyza pathaki new species (Plate 2).

Derivation of species name: Tthis species is honoured in the name of Dr. P.K. Pathak, Prof. and Head, Advisor, Entomology Dept., G.B. Pant Univ. of Agri. and Tech., Pantnagar, Nainital, U.P., India.
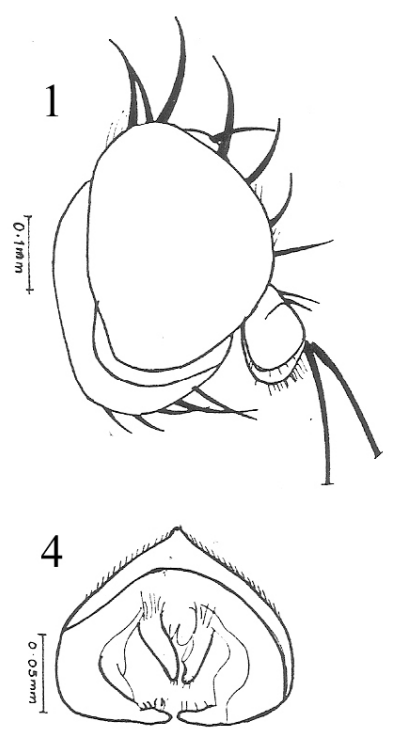
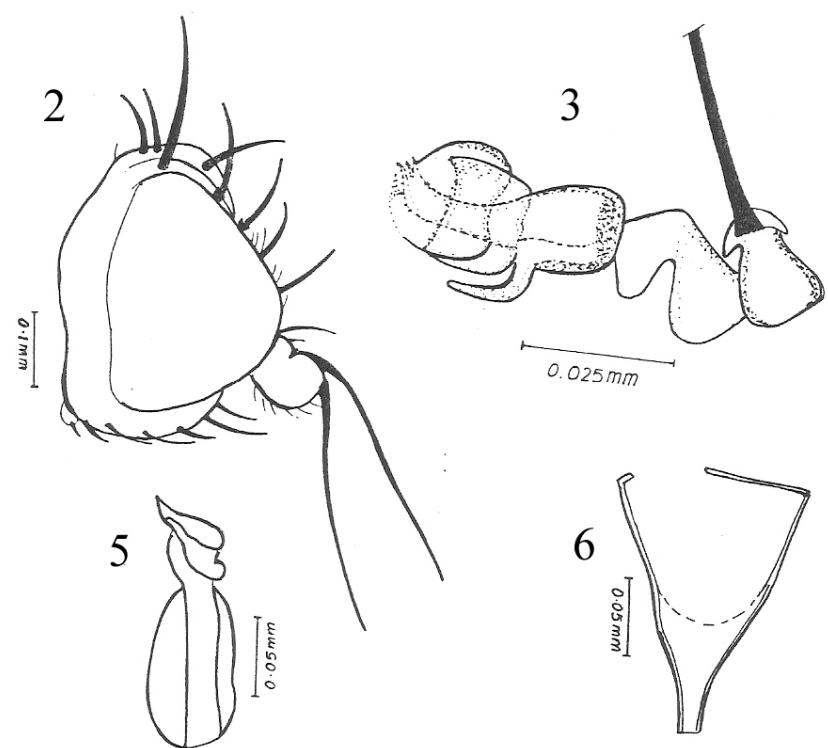

Plate 2. Melanagromyza pathaki Species nova

Comparison: The members of this species are not remarkably different on their adult external morphology with other related internal stem feeders of this region. However, the members are distinctive in having antennal bases widely separated, lunule broad and semicircular, frons and orbits not projected in profile. The aedeagus is very much distinctive as in figure 3 , with a characteristic hook like lateral process on distiphallus. Spencer (1963) has described Cassiae on related host Cassia bicapsularis Linn. from Australia. Later on, Cassiae has been transferred to Ophiomyia Braschnikov (Spencer, 1977). The members of this species differ from those of Cassiae in habing frons relatively narrower, third antennal article longer than broad, distinctive aedeagus as in figure 3, not black. The unusual lateral process of distiphallus do not agree with cassiae Spencer. Kato (1961) had described shibatsuji on Glycin max. Merrill and a related wild plant Glycin soja Sieb. at Zucc. from Japan. The distinctive aedeagus of shibatsuji as illustrated by Kato (1961) is also characterized by a spine-like long projection at the middle of distiphallus on dorsal surface. However, the members of this species differ from those of shibatsuji in having relatively narrow frons, lunule broad and semicircular, third antennal article longer than broad, halters grey. 
Diagnostic characters: Frons equal to the width of eye, lunule broad and semicircular, antennal bases widley separated, halters grey and distiphallus with a characteristic hook like projection.

Mesonotum: Two dorsocentrals. Wing (Damaged)

Male genitalia as in figures 3-6. Hypandrium (Fig. 6) with short and broad apodeme; epandrium (Fig. 4) cerci with bristles, surstyli with spines; aedeagus (Fig. 3) distiphallus with a characteristic hook like unusual process; ejaculatory apodeme (Fig. 5) long, stout, broad, blades extended.

Colour: Halters grey.

Biology: The adult fly has been reared from stem of Cassia sp. during the month of November. Ex-puparium could not be detected.

Incidence of this species is very low.

Geographical distribution: I examined the following material from Uttar Pradesh, India. Uttar Pradesh: Holotype 0 Pantnagar, Nainital, from stem of Cassia sp. coll. 3. xi. 87. emerged 5.xi.87.

\section{Melangagromyza sp.n. ex stems of Glycine max. (Linn.) Merril.}

Proposed name: Melanagromyza glycini new species (Plate 3)

Derivation of specific name: This species is named after the genus of larval food plant, Glycine max. (Linn.) Merril.

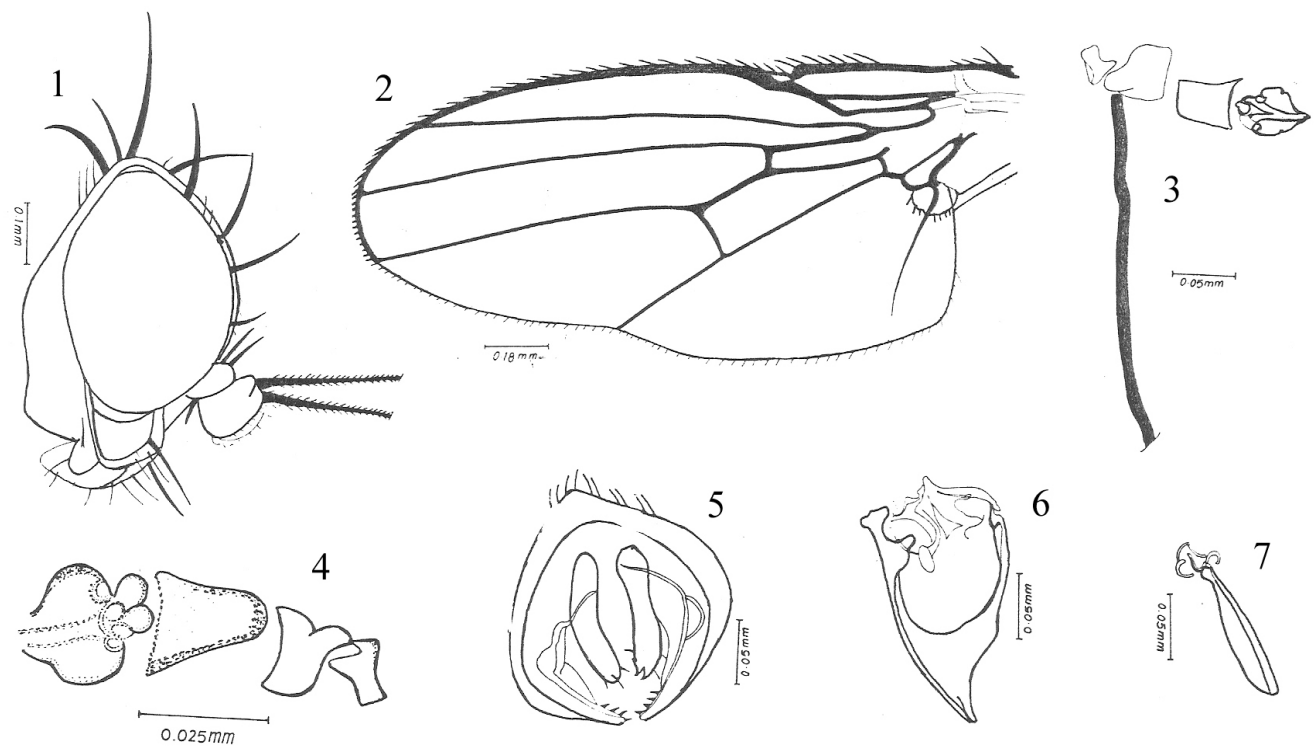

Plate 3. Melanagromyza glycini Species nova

Comparison: The members of this species differ from those of a similar species $M$. sp. n. ex stems of Pisum sativum Linn in having conspicuously elongated third antennal article with additional spine; smaller wing length; squammae silver white, margin and fringes white. The external morphological characters like distinctive third antennal article; 2 approximately equal, strong ori and genitalia characters narrow, long hypandrial apodeme readily distinguishes them from other stem feeder of this region. The aedeagus as in figure 4 lacks characteristic lobes and loops of sojae (Zehntner). The external morphological and genitalia characters distinguish them from fabae, 
which has been described and illustrated by Spencer (1973) on Vicia faba Linn. from England.

Male genitalia as in figures 3-7. Hypandrium (Fig. 6) small, side arms narrow, apodeme, small; epadrium (Fig. 5) cerci long with bristles, surstyli with spines; aedeagus as in figs. 3-4; ejaculatory apodeme (Fig. 7) long and broad, bulb small, well sclerotized.

Biology: The larvae of this species feed inside stems of Glycine max. (Linn.) Merr. during the months of October-November. Pupation takes place inside stem. Incidence of this species is very low.

Geographical distribution: I examined the following material from Uttar Prades, India.

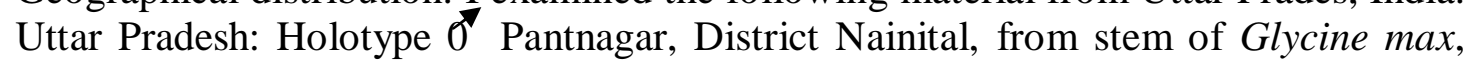
(Linn.) Merr., Coll. 21.x.87, emerged 4.xi.87.

\section{Melanagromyza sp.n. ex stems of Medicago denticulata willd.}

Proposed name: Melanagromyza denticulata new species (Plate 4).

Derivation of specific name: This species is named after the larval host plant, Medicago denticulata willd.
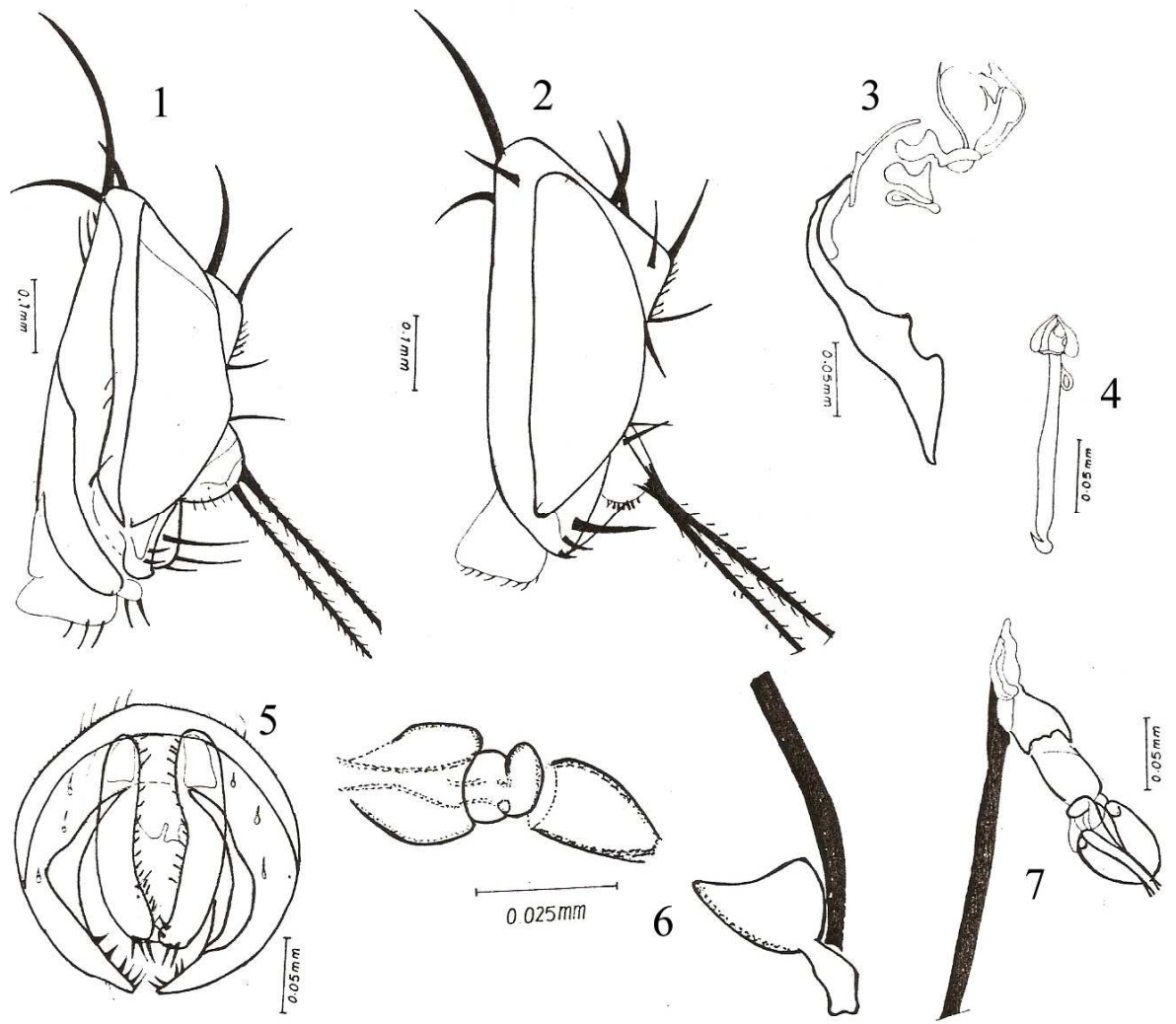

Plate 4. Melanagromyza denticulata Species nova

Comparison: The members of this species differ from those of similar species $M$. sp.n. ex Pisum sativum Linn. in having laterally compressed eye, 2.75 times higher than their lengths; smallar wing length $1.68 \mathrm{~mm}$ in male; orbits characteristically projected in front of eye margin (Figs. 1-2). Aedeagus of these two species broadly agree. However, the shape of bladder and mesophallus configuration differs. External morphology of head and characters of genitalia readily distinguishes the member of 
this species from other related species of this region and fabae Spencer described from England. Aedeagus of fabae has been illustrated by Spencer (1973).

Diagnostic characters: Orbits characteristically project infront of eye margin in profile (Figs. 1-2) 1 ori small; wing length $1.68 \mathrm{~mm}$ in male; eyes laterally compressed, 2.75 times higher than their lengths; squammae brownish; margin and fringes white; frons, orbits, ocellar triangle, antennal bases with whitish glazz.

Male genitalia as in figures 3-7. Hypandrium (Fig. 3) with narrow side arms, apodeme not extended; Epandrium (Fig. 5) cerci with bristles, surstyli with spines; aedeagus (Figs. 6-7) basiphallus close to distiphallus complex, ventral bladder rotating to right; ejaculatory apodeme (Fig. 4) long, narrow, bulb large and sclerotized.

Biology: Larvae of this species feed in side stems of Medicago denticulata willd, during the months of March-April. Pupation takes place inside stems. Incidence of this species is low.

Geographical distribution: I examined the following material from Uttar Pradesh,

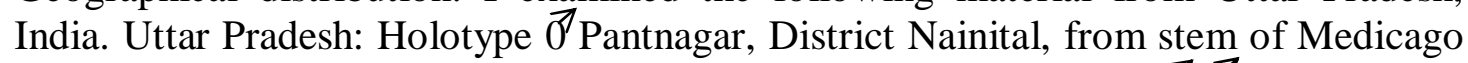
denticulata willd., Coll. 26. iii. 88, emerged 11. iv. 88; Paratypes: $19 \overrightarrow{0} 0^{7}$ same locality and host, same data, emerged 2-11. iv. 88.

\section{Melanagromyza sp.n. ex stems of Pisum sativum Linn.}

Proposed name: Melanagromyza pisiphaga new species (Plate 5).

Derivation of specific name: This species is named after the larval host plant, Pisum sativum Linn.

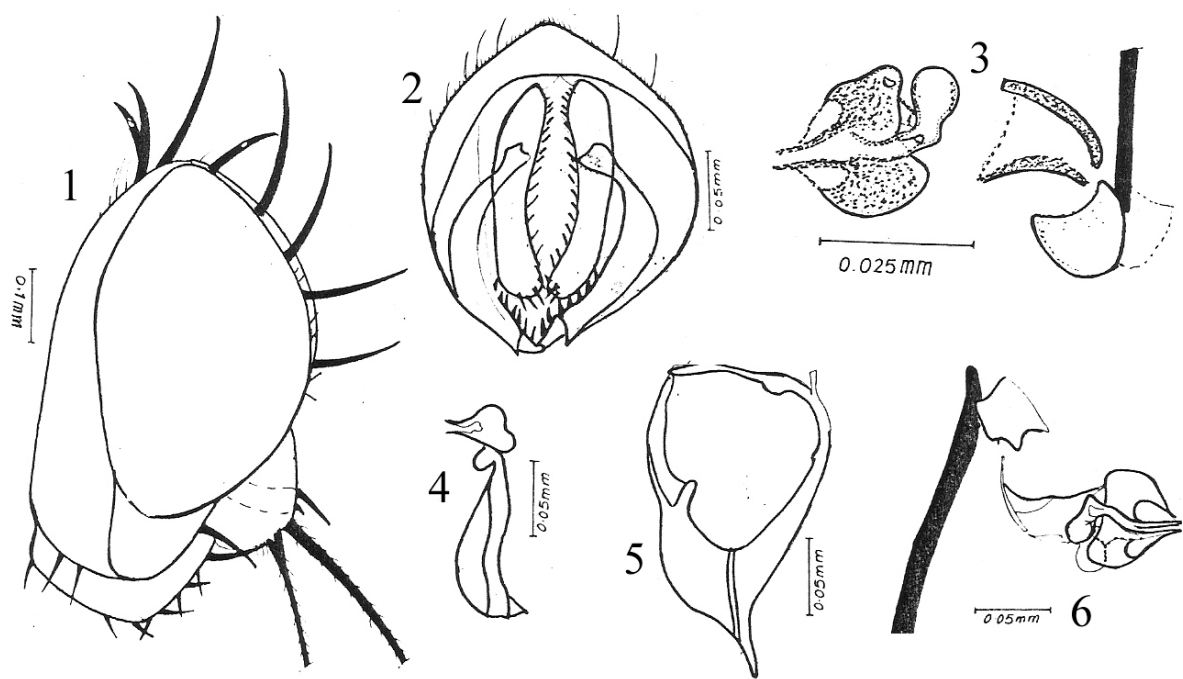

Plate 5. Melanagromyza pisiphaga Species nova

Comparison: The members of this species differ from those of sojae (Zehntner) in having the orbits projected infront of eye margin, and distinctive characters of genitalia. The members of this species differ from those of similar species $M$. sp.n. ex. stems of Medicago denticulata willd. in having larger wing length $2.1 \mathrm{~mm}$ in males, eye oval, 1.61 times higher than their lengths, frons equal to width of eye, apart from reclinate os. 1 or 2 proclinate hairs also present, orbit as in figure 1; Aedeagus as in figures. 3 and 6 with relatively more globular ventral bladder. The members of this species also differ from those of M. sp.n. ex stems of Glycine $\max$ (Linn.) Merril in having larger wing length; 
third antennal article slightly longer than broad, without additional spine, squammae brownish and with distinct characters of genitalia.

The adult external morphology and characters of genitalia of the members of this species do not agree with fabae, which has been described and illustrated by Spencer (1973).

Diagnostic characters: The member of this species are medium sized, wing length 2.1 $\mathrm{mm}$ in male, 2 ori, strong, gena 1/5.25 vertical height of eye; ocellar bristles shorter and stout; basiphallus close to distiphallus complex, squammae brownish, margin and fringes white.

Mesonotum: Two dc; acr numerous. Wing: Length $2.1 \mathrm{~mm}$ in male; subcosta joining $\mathrm{R}_{1}$; costa extended to $\mathrm{M}_{1+2}$; costal segments 2-4 in the ratio 1: $0.28: 0.2$; cross vein $\mathrm{m}-\mathrm{m}$ present; distal section of $\mathrm{M}_{3+4} 0.8$ time basal.

Male genitalia as in figures 2-6. Hypandrium (Fig. 5) with narrow side arms, apodeme short and narrow; Epandrium (Fig. 2) cerci long with bristles, surstyli with spines; aedeagus (Figs. $3 \& 6$ ) basiphallus close to distiphallus complex; distiphallus with globular bladder highly rotating towards right; basal portion of lateral lobes broader; ejaculatory apodeme (Fig. 4) broad, bulb large.

Colour: Frons black; orbits and ocellar triangle black; lunule black; antennae black; mesonotum black; scutellum black; halters black; legs greyish; squammae brownish, margin and fringes white; gena black, ocelli red.

Biology: The larvae of this species feed inside stems of Pisum sativum Linn. during December-January. Pupation also takes place inside the stem. Incidence of this species is very low.

Geographical distribution: I examined the following material from Uttar Pradesh, India. Uttar Pradesh: Holotype $\circledast$ Pantnagar, District Nainital, from stem of Pisum sativum Linn. Coll. 20. xii. 87, emerged 10. i. 88.

\section{Melanagromyza sp.n. ex stems of Trifolium pratense Linn.}

Proposed name: Melanagromyza sehgali new species (Plate 6).

Derivation of specific name: This species sehgali is honoured in the name of Dr. V.K. Sehgal, Associate Professor and Advisor, Dept. of Entomology, G.B. Pant Univ. of Agri. and Tech., Pantanagar, Nainital, U.P., India.

Comparison: The members of this species differ from those of sp.n. ex. stems of Glycine max. (Linn.) Merr. in having frons equal to the width of eye, not projected beyond eye in profile, without proclinate hairs, third antennal article without an additional spine, orbit not projecting infront of eye margin in profile.

Male genitalia characters are also distinctive, hypandrium with long and narrow apodeme. External morphology and genitalia characters of the members of this species also differ from those of $M$. sp.n. ex stems of Pisum sativum Linn. and $M$. sp.n. ex stem of Medicago denticulata willd. Genitalia characters of the members of this species differ from those of sojae, aedeagus (Fig. 4) lacks characteristic lobes and loops. External morphology and characters of genitalia also differ with fabae, as described and illustrated by Spencer (1973) on Vicia faba Linn. from England.

Diagnostic characters: The members of this species are having 2 ori, almost equal and strong; frons and orbits not projected in profile; gena relatively broader $1 / 5.5$ vertical 
height of eye; wing length $1.89 \mathrm{~mm}$ in male; hypandrial apodeme narrow and elongated.

Male genitalia: Hypandrium (Fig. 2) with broad side arms, apodeme narrow and long; epandrium (Fig. 3) cerci long with bristles, surstyli, with spines; aedeagus as in (Fig. 4), ejaculatory apodeme (Fig. 5) long, broad, blades extended, bulb large.

Biology: The larvae of this species feed inside stems of Trifolium pratense Linn. during the months of October. Pupation also takes place inside stem. Incidence is very low.

Geographical distribution: I examined the following materials from Uttar Pradesh, India. Uttar Pradesh: Holotype 0 Pantnagar, District Nainital, from stem of Trifolium pratense Linn., Coll. 3. x. 87, emerged 7. x. 87; Paratype: 1 same Data, Coll. 2. v. 87, emerged 12. v. 87.
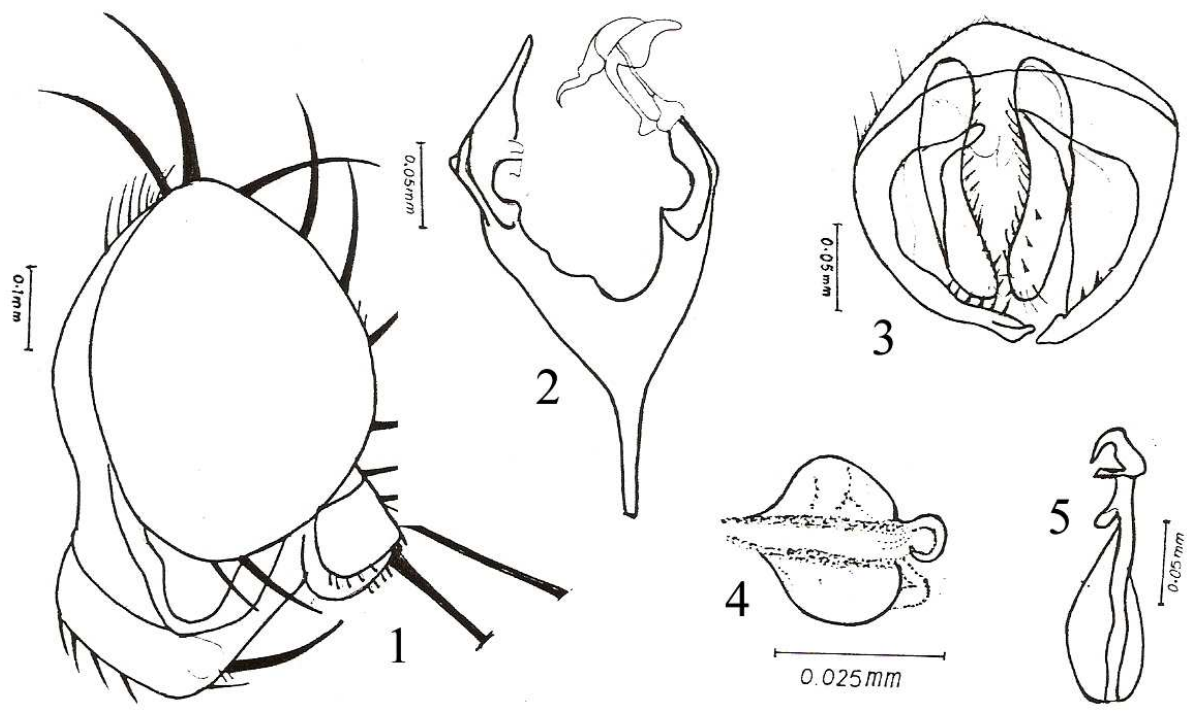

Plate 6. Melanagromyza sehgali Species nova

\section{Melanagromyza sp.n. ex stems of Vicia faba Linn.}

Proposed name: Melanagromyza vicivora new species (Plate 7).

Derivation of specific name: This species is named after the larval food plant, Vicia faba Linn.

Comparison: The members of this species are close to those of sojae (Zehntner) in external morphology. However, characters of male genitalia are distinctive in having less prominent loop, bladder more curved and extended far beyond the rear of mosophallus as in figure 5 (later view). The genitalia characters readily distinguish them from other Melanagromyza complex of this region. Spencer (1973) has described and illustrated genitalia of fabae on the same host from England. The members of the species described here are smaller and; remarkably differ from fabae in having only 2 ori, os sparse; eyes bare, jowls not deepest in centre below eye; wing length $1.68 \mathrm{~mm}$; squammae, margin and fringes white; but broadly agree with gena: eye height ratio. Genitalia differences are more remarkable in having bladder extending far beyond the rear of mesophallus. In fabae bladder extending slightly beyond rear of mesophallus. The members of this species differ with M. azawii sp.n. in external morphological and genitalic characters. Spencer (1973) has described $M$. azawii from stems of Vicia faba in Iraq. 
Diagnostic characters: The members of this species are small sized, wing length 1.68 $\mathrm{mm}$; third and 4th costal segments are equal; lower ori quite small, ocellar triangle large, gena relatively broad 1/4.2 vertical height of eye.

Male genitalia as in figures 3-6. Hypandrium (Fig. 6) Y shaped with broad and long side arms, apodeme broad and short; epandrium (Fig. 4) cerci long with bristles, surstyli with spines; aedeagus (Fig. 5) basiphallus separated by a wide gap, distiphallus with relatively more curved ventral bladder, extending far beyond rear of mesophallus, the loop in not so distinct; ejaculatory apodeme (Fig. 3) long and broad, bulb large with well sclerotization.

Colour: Frons black; orbits and ocellar triangle black; lunule black; antennae black; mesonotum black; scutellum black; halters grey; legs black; squammae silver white, margin and fringes white.

Biology: The larvae of this species feed inside stems of Vicia faba Linn., during the months of March-April. Incidence of this species is very low.

Geographical distribution: I examined the following material from Uttar Pradesh, India. Uttar Pradesh: Holotype 0 Pantnagar, District Nainital, from stems of Vicia faba Linn., Coll, 16. iii. 88, emerged 13. iv. 88; 13. iv. 88; Paratype: 1 q same locality and host, Coll. same data, emerged 23. iii. 88.
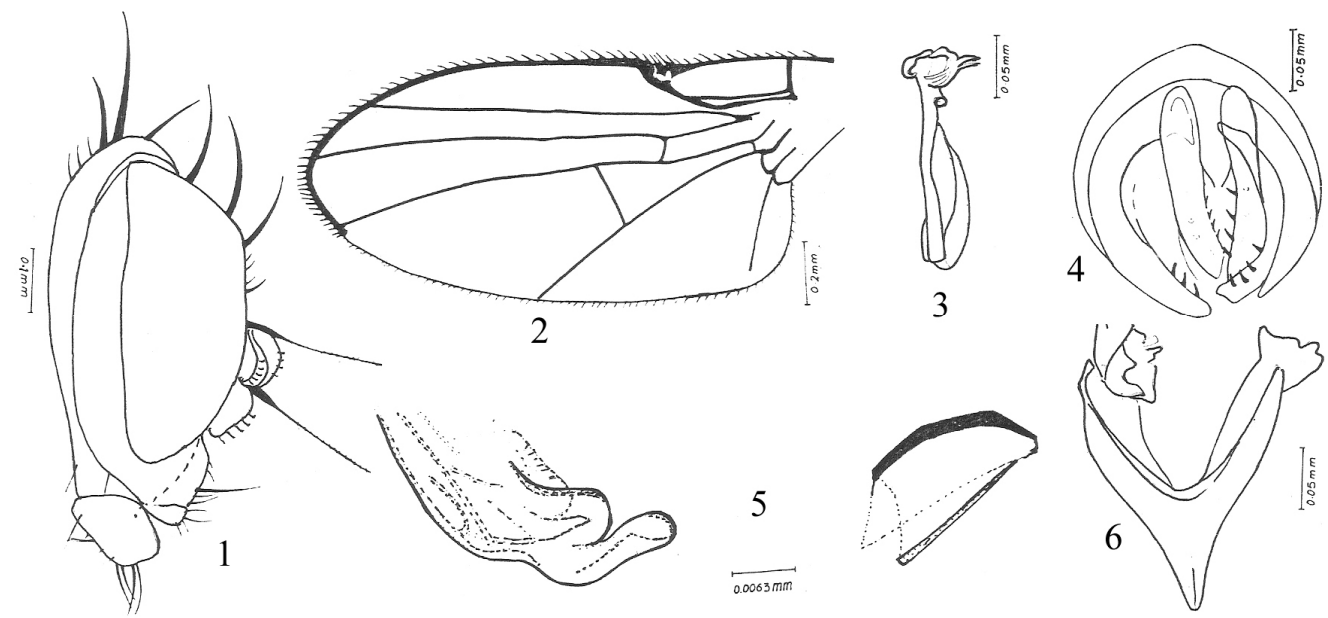

Plate 7. Melanagromyza vicivora Species nova

\section{Ophiomyia sp.n. ex stems of Pueraria phaseoloides (Roxb.) Benth.}

Proposed name: Ophiomyia puerariae new species (Plate 8).

Derivation of specific name: This species is named after the genus of larval food plant. Pueraria phaseoloides (Roxb.) Benth.

Comparison: The members of this species differ from those of a similar species centrosematis (de Meijere) in having relatively narrow gena, $1 / 10.5$ vertical height of eye, and with distinctive genitalia characters. The aedeagus of centrosematis (de Meijere) has been figured by Spencer $(1973,1977)$ and Greathead (1969).

The members of this species also differ with those of another similar species $O$. sp.n. ex stems of Sesbania aculeata Pers. in gena eye height ratio and genitalia characters. The characteristic aedeagus of $O$. sp.n. ex stems of Sesbania aculeata Pers. has only one selerotic arm. The male members of this species lacks vibrissal fasciculus, thus they differ 
from true Ophiomyia, cicerivora Spencer. The relatively narrow gena, small and not shining ocellar triangle readily segregates these members from those of phaseoli (Tryon).

Diagnostic characters: Small black species; wing length $1.47 \mathrm{~mm}$ in male gena relatively narrow 1/10.5 vertical height of eye; squammae white, margin and fringes black; one sclerotic arm of basiphallus shifted towards bladder; basiphallus relatively globular.

Male genitalia as in figures 4-7. Hypandrium (Fig. 5) with narrow side arms, apodeme not extended; epandrium (Fig. 6) cerci without bristles, Surstyli with spines; aedeagus (Fig. 4) distinctive basiphallus with asymmetrical sclerotic arms, one arm which arises on left side shiftted towards bladder; bladder relatively globular; distiphallus asymmetrical; ejaculatory apodeme narrow, blades not extended.

Colour: Mesonotum black; scutellum black; halters black; squammae white, margin and fringes black.

Biology: Reared from stem of Pueraria phaseoloides (Roxb.) Benth, during the months of March-April. Ex-puparia colud not be detected.

Geographical distribution: I examined the following material with genitalia preparation fro Uttar Pradesh, India. Uttar Pradesh: Holotype 07 Pantnagar, District Nainital, from stems of Pueraria phaseoloides (Roxb.) Benth, Coll. 26. viii. 87, emerged 4. ix. 87.

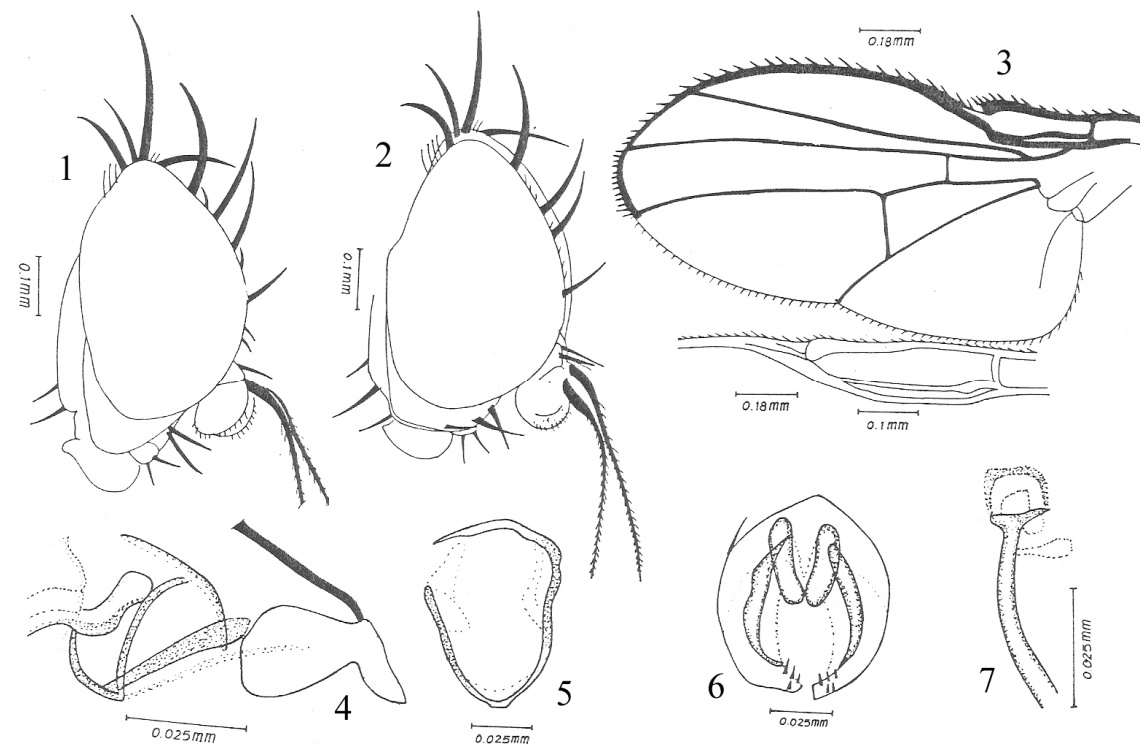

Plate 8. Ophiomyia puerariae Species nova

\section{Ophiomyia sp.n. ex stems of Sesbania aculeata Pers.}

Proposed name: Ophiomyia sesbaniae new species (Plate 9).

Derivation of specific name: this species is named after the genus of larval food plant, Sesbania aculeata Pers.

Comparison: The members of this species differ with those of a similar species centrosematis (de Meijere) and $O$. sp.n. ex stems of pueraria phaseoloides (Roxb.) Benth. in distinctive genitalia characters. The aedeagus as in figure 2 with only one sclerotic arm. The members of this species are having relatively broad gena, and thus they differ from those of $O$. sp.n. ex stems of Pueraria Phaseoloides (Roxb.) Benth. The aedeagus of 
centrosematis (de Meijere) has been figured by Spencer (1963, 1973, 1977) and Greathead (1969). The male members of this species lack vibrissal fasciculus, which is characteristic feature of cicerivora Spencer. The members of this species also differ from those of phaseoli (Tryon) in having small ocellar triangle, which do not shine.

Diagnostic characters: Small black species; gena relatively broad, 1/5.3 vertical height of eye; ocellar triangle small and sunken; squammae white, margin and fringes black; apart from numerous reclinate os, few proclimate hairs also present; basiphallus with a single sclerotic, asymmetrical arm.

Male genitalia as in figures 2-5. Hypandrium (Fig. 3) with slender and long side arms, apodeme not extended; epandrium (Fig. 4) cerci with bristles, surstyle with spines; aedeagus (Fig. 2) basiphallus with a single selerotic, asymmetrical arm; distiphallus relatively symmetrical; ejaculatory apodeme small, narrow blades not extended, bulb small, well secerotized.

Colour: Halters black, squammae white, margin and fringes black.

Biology: Larvae mines the stems of Sesbania aculeata Pers. during August.

Geographical distribution: I examined the following material with genitalia preparation from Uttar Pradesh, India. Uttar Pradesh: Holotype 07Pantnagar District Nainital, from stem surface mine of Sesbania aculeata Pers., Coll. 4.ix.87, emerged 12.ix.87; Paratypes: 4 不

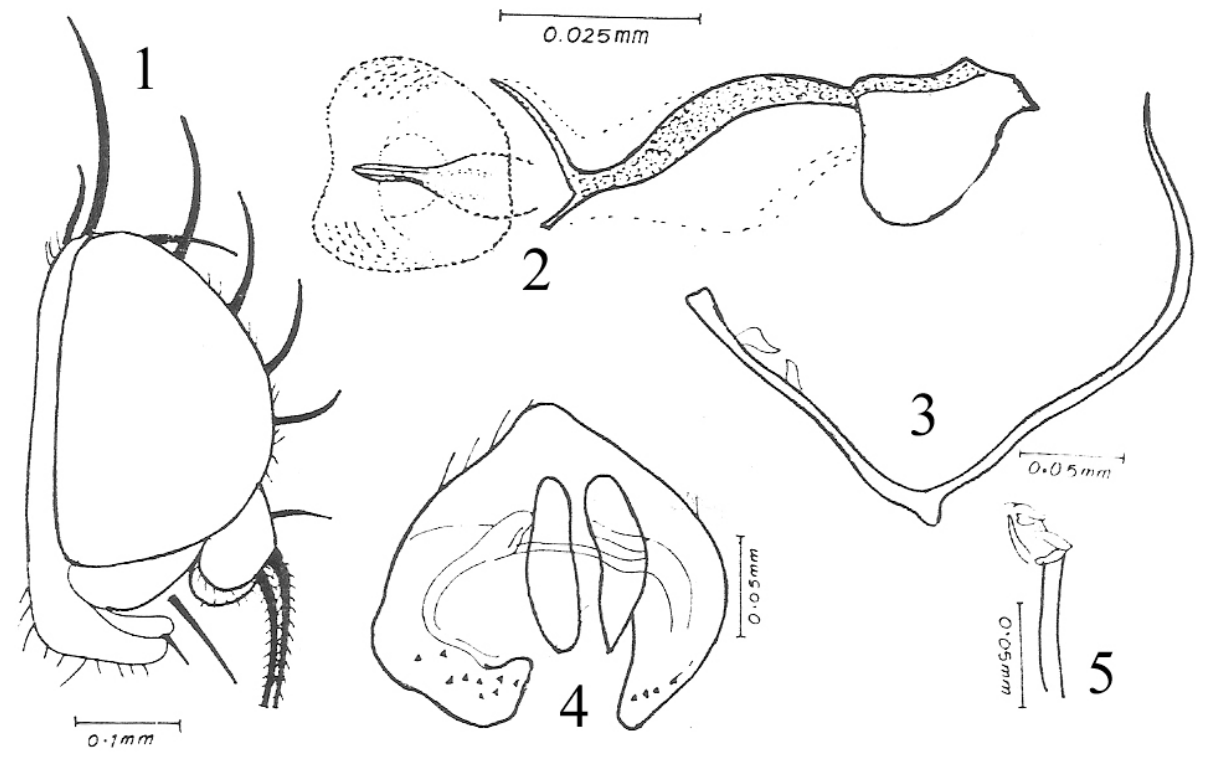

Plate 9. Ophiomyia sesbaniae Species nova

\section{Ophiomyia sp.n. ex stems of Vigna mungo Linn.}

Proposed name: Ophiomyia mungivora new species (Plate 10)

Derivation of specific name: The name of this species is named after the species of larval food plant, Vigna mungo Linn.

Comparison: The members of this species differ from those of a similar species phaseoli (Tryon) in having third antennal article conspicuously elongated, ocellar triangle, frontal vitta do not shine, and with highly distinctive aedeagus as in figure 3 . The characteristic aedeagus of phaseoli (Tryon) has been figured by Spencer (1963, 1973, 1977) and Greathead (1969). The members of this species also differ with 
another related species $O$. sp.n. ex stems of Vigna mungo (Linn.) Heeper in having 2 unequal ori, lower one much smaller and incurved; third antennal article conspicuously elongated; frons relatively wider, equal to the width of eye; carci with bristles; ejaculatory apodeme quite broad and with distinctive aedeagus (Fig. 3). The male members of this species lack vibrissal fasciculus thus they differ from these of cicerivora Spencer. The distinctive characters of genitalia readily segregate them from those of centrosematis (de Meijere). The aedeagus of centrosematis has been figured by Spencer $(1963,1973,1977)$ and Greathead (1969). The aedeagus of this species (Fig. 3) do not agree with the aedeagus of spencerella (Greathead), which has been illustrated by Spencer (1973) and Greathead (1969).
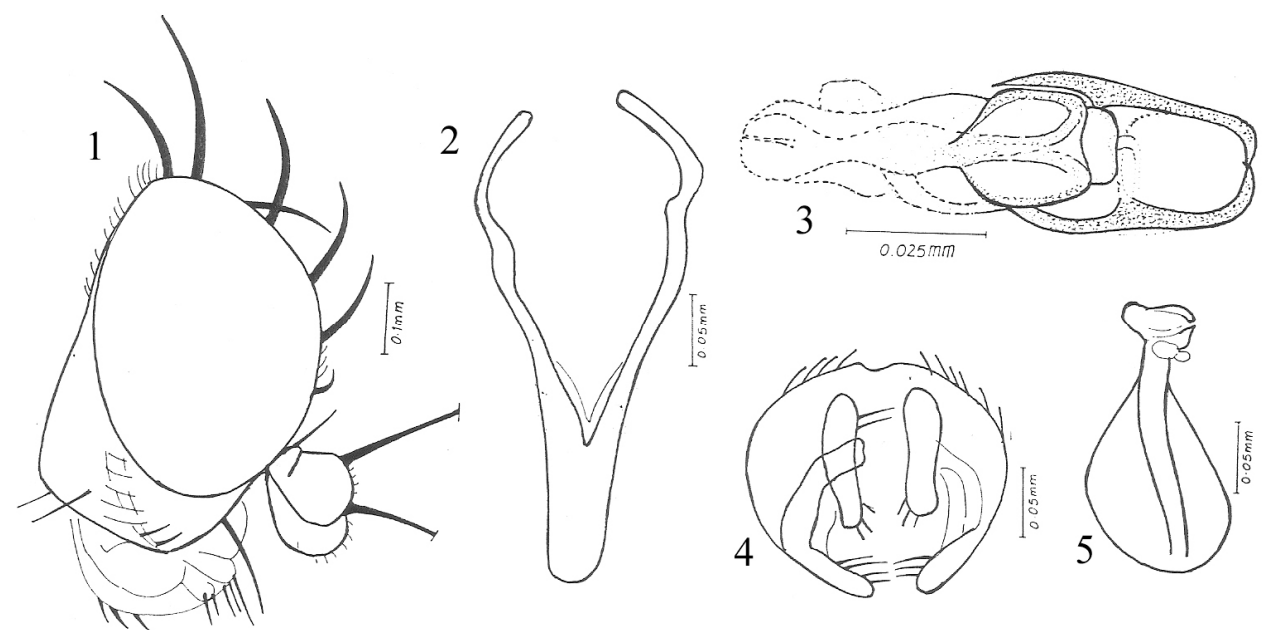

Plate 10. Ophiomyia mungivora Species nova

Diagnostic characters: The members of this are medium sized, wing length $1.84 \mathrm{~mm}$; gena relatively broad, $1 / 5.5$ vertical height of eye; third antennal article conspicuously elongated; lunule reflects greyish white, squammae silver white, margin and fringes white; halters black.

Description: Head (Fig. 1) width of frons $0.21 \mathrm{~mm}$, equal to the width of eye at the level of front median ocellus, not projected beyond eye in profile; 2 ori, unequal, lower one much smaller, incurved; 2 ors, strong, incurved, directed upwards; orbital setulae numerous, reclinate; eyes oval, bare; lunule broad; antennal bases separated; fascial keel absent; vibrissae numerous; eye $0.462 \mathrm{~mm}, 1.37$ times higher then their lengths; gena $0.084 \mathrm{~mm}, 1 / 5.5$ vertical height of eye; ocellar triangle small, ocellar bristles strong; orbits normal, at level of the plane of frons, not projected infront of eye margin in profile; third antennal article conspicuously elongated with an angle, spine anterodorsally directed, pubescence conspicuously large; arista long, bare.

Male genitalia (Figs. 2-5), Hypandrium (Fig. 2) apodeme quite borad, side arms narrow; epandrium (Fig. 4) cerci with bristles, surstyli with spines; aedeagus (Fig. 3) basiphallus with symmetrical sclerotic arms, extended to enclose a part of distiphallus complex (in ventral view), close to distiphallus complex; mesophallus is in the form of bladder; distiphallus with a broad sclerotized portion, terminal end is continued as a long broad, and less sclerotized structure; ejaculatory apodeme (Fig. 5) quite broad, blades will extended, bulb large well sclerotized.

Biology: Reared from stem of Vigna mungo (Linn.) Heeper during November. Expuparium could not be collected. Incidence of this species is very low. 
Geographical distribution: I examined the following material with genitalia preparation from Uttar Pradesh, India. Uttar Pradesh: Holotype $\$ Pantnagar, District Nainital, from stem of Vigna mungo (Linn.) Heeper, Coll. 7. xii. 87, emerged 29. xii. 87.

\section{Ophiomyia sp.n. ex stems of Vigna mungo (Linn.)}

Proposed name: Ophiomyia spenceri new species (Plate 11).

Derivation of specific name: This species is honoured to Dr. K.A. Spencer, in recognition of the contributions made by him to our knowledge of World Agromyzidae.

Comparison: The members of this species differ from a similar species phaseoli (Tryon) in having brownish squammae, margin and fringes white; ocellar triangle not shining; frontal vitta bleck; lunule whitish grey; cerci without bristles and with distinctive aedeagus as in figure 6 . The aedeagus of phaseoli (Tryon) has been figured by Greathead (1969) and Spencer (1963, 1973, 1977). The members of this species also differ from those of another related species $O$. sp.n. ex stems Vigna mungo (Linn.) Heeper in having ori appromicately equal, strong; third antennal article round; squammae brownish; frons relatively narrow and with distinctive characters of genitalia (Fig. 6). The aedeagus of this species readily differ from aedeagus of spencerella (Greathead), which has been figured by Greathead (1969) and Spencer (1973). The male members of this species lack vibrissal fasciculus and thus they differ from cicerivora Spencer. The members of this species also differ from those of centrosematis (de Meijere) in having broad lunule, large ocellar triangle, cerci without bristles and with distinctive characters of genitalia.
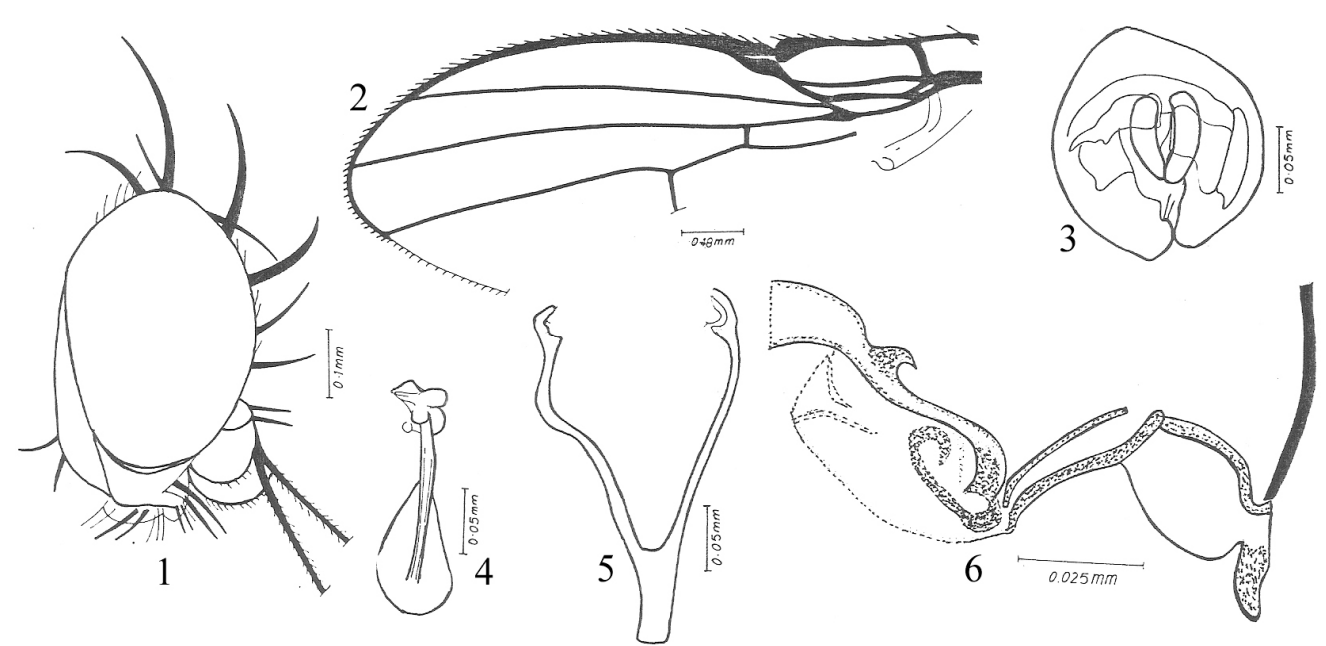

Plate 11. Ophiomyia spenceri Species nova

Male genitalia as in figures 3-6. Hypandrium (Fig. 5), with narrow side arms, apodeme extended and broad; epandrium (Fig. 3) cerci shorter, without bristles, surstyli with few spines; aedeagus (Fig. 6) basiphallus with two long, unequal arms, close to distiphallus complex; mesophallus inconspicuous; distiphallus long, asymmetrical, with a characteristic spine; ejaculatory apodeme (Fig. 4) long, broad, blades extended, bulb large, sclerotized.

Biology: Reared from stem of Vigna mungo (Linn.) Heeper during the months of October-November. Ex-puparia could not be collected. Incidence of this species is very low. 
Geographical distribution: I examined the following material with genitalia preparation from Uttar Pradesh, India. Uttar Pradesh: Holotype 0 Pantnagar, District Nainital, from stem of Vigna mungo (Linn.) Heeper, Coll. 24. x. 87, emerged 31. x. 87.

\section{Liriomyza sp.n. ex leaves of Vicia fabae Linn.}

Proposed name: Liriomyza fabae new species (Plate 12).

Derivation of specific name: The name of this species is after the species of larval food plants, Vicia faba Linn.

Comparison: The members of this species differ from those of $L$. sp.n. ex leaves of Vicia sativa Linn. and strigata (Meigen) in having frons equal of width of eye, third antennal article conspicuously elongated, with an angle and distinctive characters of the genitalia. This species differ from members of bryoniae (Kaltenbench) and brassicae (Riley) in having larger wing length, and characters of genitalia. The members of this species also differ from tarai Garg in having relatively narrower frons, equal to the width of eye; lunule raised and black; squammal margin and fringes black. The aedeagus of strigata (Meigen), bryoniae and brassicae (Riley) has been illustrated by Spencer (1973).

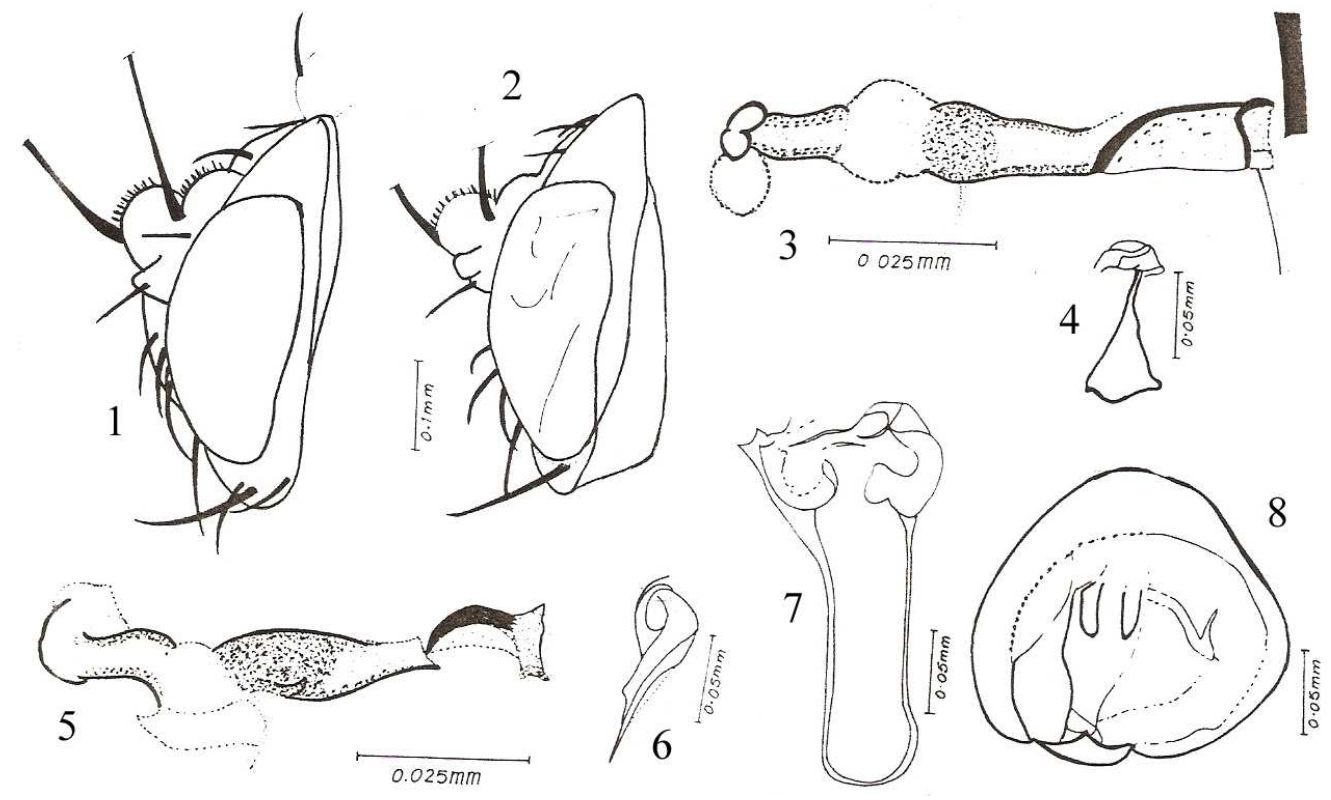

Plate 12. Liriomyza fabae Species nova

Diagnostic characters: Medium sized species, wing length $1.659 \mathrm{~mm}$ in male, gena 1/3.2 vertical height of eye, distal section of $\mathrm{M}_{3+4} 1.92$ times longer than basal portion; frons yellow, antennae yellow with raddish tinge, lunule black.

Male genitalia as in figures 3-5 and 7-8. Hypandrium (Fig. 7) U shape, side arms narrow; epandrium (Fig. 8), cerci small without bristles, surstyli without spines; aedeagus (Figs. 3, 5) basiphallus elongate, distiphallus with two asymmetrical apertures and a weakly sclerotized circular ring; ejaculatory apodeme (Fig. 4) minute with small bulb.

Biology: The larvae of this species make linear mines on the leaves of Vicia faba Linn. during March-April. 
Geographical distribution: I examined the following material from Uttar Pradesh, India. Uttar Pradesh: Holotype $\widehat{O}$ Pantnagar, District Nainital, from leaf mines on Vicia faba Linn., Coll. 1. iv. 88, emerged 5. iv. 88.

\section{Liriomyza sp.n. ex leaves of Vicia sativa Linn.}

Proposed name: Liriomyza pantnagarensis new species (Plate 13).

Derivation of specific name: The name of this species is after the type locality, Gobind Ballabh Pant University of Agriculture and Tech., Pantnagar, Nainital, U.P., India.

Comparison: The members of this species differ from L. sp.n. ex leaves of Vicia faba Linn, in having narrow frons, wing length 1.134-1.176 mm, and distinctive characters of aedeagus. This species differ from strigata (Meigen) in having small wing length, much developed third antennal article, and with distinctive characters of aedeagus. The members of this species also differ from those of bryoniae (Kaltenbanch) in having smaller wing length; distal section of $\mathrm{M}_{3+4}$ 2.62-3 times longer than basal portion.

This species is similar to the members of brassicae in having sunken lunule, and third antennal article without angle, however genitalia characters are distinctive. The aedeagus of strigata (Meigen), bryoniae (Kaltenbanch), and brassicae (Riley) have been illustrated by Spencer (1973). The members of this species also differ from those of tarai garg in having smaller wing length and narrower frons than width of eye. Garg (1971) has described tarai from Vicia sativa Linn. on the basis of 3 females.

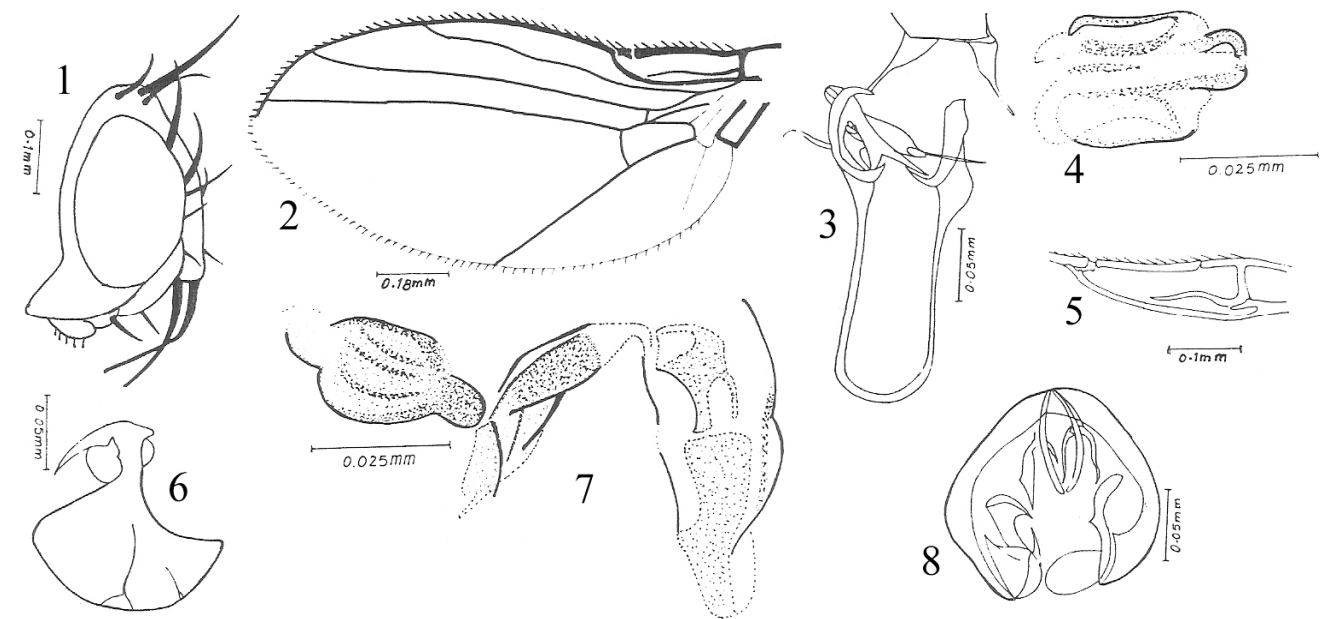

Plate 13. Liriomyza pantnagarensis Species nova

Diagnostic characters: The members of this species are small in size, gena 1/2.41/4.666 vertical height of eye; ocellar triangle small, sunken; wing length 1.134-1.176 $\mathrm{mm}$; frons yellow; antennae yellow; lunule brownish.

Male genitalia as in figures 3-4 and 6-8. Aedeagus (Figs. 4, 7) basiphallus elongate, close to distiphallus complex; distiphallus broader, elongate with a distinct bladder; ejaculatory apodeme (Fig. 6) broad, large, blades well extended, bulb large, sclerotized.

Colour: Frons yellow; orbits yellow, ocellar triangle black; lunule brownish, antennae yellow, arista black; mesonotum black; scutellum yellow; legs yellow; halters yellow; suqammae yellow, margin and fringes black. 
Biology: The larvae of this species make blotch mines on leaves of Vicia sativa Linn. during the months of February-April. Pupation takes place on the ground.

Geographical distribution: I examined the following material from Uttar Pradesh, India. Uttar Pradesh: Holotype $\widetilde{\mho}$ Pantnagar, District Nainital, from leaf mines on Vicia faba Linn., Coll. 27. iii. 88, emerged 3. iv. 88; Lectotype: 1 9 , same data; paratypes: 7 우, same locality and host, same data, emerged 3-5. iv. 88.

\section{Acknowledgement}

I express my sincere thanks and indebted to my advisors, Dr. P.K. Pathak and Dr. V.K. Sehgal, Professors, Department of Entomology, College of Agriculture, G.B. Pant University of Agriculture and Technology, Nainital, Uttaranchal, India. I am highly indebted to Unviersity Grants Commission, India for providing me fellowship to carry this research at that University.

My sincere thanks are due to Dr. Gour and his associates, Forest Research Institute, Dehradun for identification of various host plants.

\section{References}

Frick, K.E. 1952. A generic revision of the family Agromyzidae (Deptera) with a catalogue of new world species. Univ. Calif. Publs. Ent. 8(8): 339-452.

Garg, P.K. 1971. Taxonomic studies on Agromyzidae (Diptera) from Gangetic Basin part I. Descriptions of three new species. Orient. Insects. 5: 179-188.

Greathead, D.J. 1969. A study in East Africa of the beanflies (Dipt., Agromyzidae) affecting Phaseolus vulgaris and their natural enemies, with the description of a new species of Melanagromyza Hendel. Bull. Ent. Res. 59: 541-561.

Greathead, D.J. 1971. A new species of Melanagromyza Hendel (Dipt., Agromyzidae) from pods of the bonavist bean (Dolichos lablab in Uganada). Bull. ent. Res. 60: 463-465.

Griffiths, G.C.D. 1972. Comment on steyskal's note on phytomyza horticola Goureau $P$. syngenesiae (Hardy) (Dipt., Agromyzidae). Entomol. News 83: 39-40.

Ipe, M. Ipe. 1967. A detailed morphological study of the external and internal genital organs of male Melanagromyza obtusa (Malloch), a pest of Cajanus indicus L. Agromyzidae: Deptera). Indian J. Ent. 29(1): 1-10.

Ipe, M. Ipe. 1971. Descriptions of six new species of Agromyzidae from India (Diptera). Orient. Insects. 5: 165-178.

Ipe, M. Ipe. 1978. Generic composition and distributional patterns of Agromyzidae from India (Diptera: Agromyzidae). Orient. Insects. 12(3): 339-346.

Kato, S. 1961. Taxonomic studies on soybean leaf and stem mining flies (Diptera, Agromyzidae) of economic importance in Japan, with description of three new species. Bull. Natn. Inst. Agric. Sci. (C). 13.

Khan, S.A. \& R.M. Shafique. 1974. Stem mining fly Melanagromyza phaseoli (Tyron) observed on soybean in Punjab. Agriculture Pakist. 25(1): 19-20.

Nowakowski, J.T. 1962. Introduction to a systematic revision of the family Agromyzidae (Diptera) with some remarks on host-plant selection by these flies. Annls. Zool. Warsz. 20(8): 67-183.

Sasakawa, M. 1960. A study of the Japanese Agromyzidae (Diptera). 1, Sci. Rep. Kyoto. Pref, Univ. Agri. 12: 76-82.

Sasakawa, M. 1961. A study of the Japanese Agromyzidae (Diptera), 2. Pacif. Insects. 3: 307-472.

Sasakawa, M. 1981. Agromyzidae and Clusiidae of Nepal (Diptera). Akitu 25: 10.

Sasakawa, M. 1982. Agromyzidae of thiland (Diptera). Akitu 37: 6. 
Sasakawa, M. 1986. Chinese Agromyzidae (Diptera) in Institute of Zoology, Academia Sinicica. Entomotaxonomia 8(3): 163-172.

Sehgal, V.K. 1965. Studies on Indian Agromyzidae (Diptera). Beitr. Ent. 15: 3-10.

Sehgal, V.K. 1971. A taxonomic survey of Agromyzidae (Diptera) of Alberta Canada, with observations on host-plant relationships. Quaest Ent. 7(3): 291-405.

Sehgal, V.K. 1987. A taxonomic survey of Agromyzidae (Diptera) of Alberta Canada, with observations on host-plant relationships. Quaest Ent. 7(3): 291-405.

Sehgal, V.K. 1987. Agromysae (Diptera) of Economic Importance in India and their Management. In: Recent Advances in Entomology (Eds. Y.K. Mathur et al.), Gopal Prakashan, Kanpur, India. pp. 111-140.

Sehgal, V.K., M.A. Khan, M. Jyoti, A.K. Sen \& C.K. Mandal. 1980. Survey and taxonomic studies on the Agromyzid flies (Diptera) of North India, with special reference to their host-plant relationships. Final report of ICAR Adhoc Research Scheme (1977-1980), G.B. Pant Univ. of Agric. and Tech., Pantnagar (Nainital) U.P. India, 167 p.

Singh, S. \& M. Ipe. 1971. Descriptions of two new species of Melanagromyza Hendel (Dipt., Agromyzidae) from India. Orient. Insects. 5: 223-228.

Singh, S. \& M., Ipe Ipe. 1973. Agromyzidae from India. Mem. Sch. Ent. 1: 266.

Singh, S. 1982. Ecology of the Agromyzidae (Diptera) associated with leguminous crops in India. Mem. Sch. Ent. 8: 126.

Spencer, K.A. \& G.C. Steyskal. 1986. Manual of the Agromyzidae (Eiptera) of the United States, U.S.A., U.S. Department of Agriculture, Agriculture hand book no. 638. $478 \mathrm{p}$.

Spencer, K.A. 1963. The Australian Agromyzidae (Diptera, Insecta). Rec. Aust. Mus. 15: 305- 354.

Spencer, K.A. 1964. A revision of the Palaeartic species of the Genus Ophiomyia Braschnikov (Diptera: Agromyzidae). Beitr. Ent. 14: 773-822.

Spencer, K.A. 1973. Agromyzidae (Diptera) of economic importance. Ser, Entomol. 9: 1405.

Spencer, K.A. 1977. Notes on World Agromyzidae, with the description of 16 new species (Diptera: Agromyzidae). Beitr, Ent. 27(2): 233-245.

Spencer, K.A. 1981. Agromyzidae (Diptera): in Iraq. Entomol. Gaz. 32(3): 177-180.

Spencer, K.A. 1982. Agromyzidae in Chile. Stuttg. Beitr. Naturkd. Ser. 357: 1-55.

Spencer, K.A. 1985. East African Agromyzidae (Diptera) further descriptions, revisionary notes and new records. J. Nat. Hist. 19(5): 961-1027.

Steyskal, G.C. 1972. The taxonomy of the alfalfa blotch-miner, Agromyza frontella (Rondani). Cooperative Economic Insect Report 22(11): 134-137.

Thapa, R.B. 1991. Survey and taxonomic studies on the Agromyzid flies associated with leguminous hosts at Pantnagar in the Northern India. Ph.D. Thesis, G.B. Pant University of Agriculture and Technology, Pantnagar. (Uploaded on internet). 